\title{
A Review on the Evolution of Darrieus Vertical Axis Wind Turbine: Small Wind Turbines
}

\author{
Palanisamy Mohan Kumar ${ }^{1,2 *}$, Krishnamoorthi Sivalingam ${ }^{2,3}$, Srikanth Narasimalu3, \\ Teik-Cheng Lim², Seeram Ramakrishna1, He Wei ${ }^{4}$
}

\author{
${ }^{1}$ Department of Mechanical Engineering, National University of Singapore, Singapore City, Singapore \\ ${ }^{2}$ School of Science and Technology, Singapore University of Social Sciences, Singapore City, Singapore \\ ${ }^{3}$ Innovation Centre, Nanyang Technological University, Singapore City, Singapore \\ ${ }^{4}$ Singapore Institute of Manufacturing Technology, Singapore city, Singapore \\ Email: ^mohan@nus.edu.sg, to_mohankumar@yahoo.com
}

How to cite this paper: Kumar, P.M., Sivalingam, K., Narasimalu, S., Lim, T.-C., Ramakrishna, S. and Wei, H. (2019) A Review on the Evolution of Darrieus Vertical Axis Wind Turbine: Small Wind Turbines. Journal of Power and Energy Engineering, 7, 27-44.

https://doi.org/10.4236/jpee.2019.74002

Received: March 31, 2019

Accepted: April 25, 2019

Published: April 28, 2019

Copyright $\odot 2019$ by author(s) and Scientific Research Publishing Inc. This work is licensed under the Creative Commons Attribution International License (CC BY 4.0).

http://creativecommons.org/licenses/by/4.0/

\begin{abstract}
Wind energy witnessed tremendous growth in the past decade and emerged as the most sought renewable energy source after solar energy. Though the Horizontal Axis Wind Turbines (HAWT) is preferred for multi-megawatt power generation, Vertical Axis Wind Turbines (VAWT) is as competitive as HAWT. The current study aims to summarize the development of VAWT, in particular, Darrieus turbine from the past to the project that is underway. The reason for the technical challenges and past failures are discussed. Various configurations of VAWT have been assessed in terms of reliability, components and low wind speed performance. Innovative concepts and the feasibility to scale up for megawatt electricity generation, especially in offshore environments are investigated. This paper is a modest attempt to highlight the state-of-the-art information on the ongoing developments focusing on decentralized power generation. This review is envisioned as an information hub for the major developments in VAWT and its technical advancements so far.
\end{abstract}

\section{Keywords}

Wind Turbine, Darrieus, Savonius, TSR, Vertical Axis, Wind Load, Deep Stall, Wake

\section{Introduction}

History of wind turbines dates back to 7th century in Afghanistan, 9th century in Persia [1] followed by the introduction of HAWT around 12th century in Europe. Despite notable innovations do happen afterwards, it was not until 
1970, wind turbines are recognized for power generation during the energy crisis [2]. The need for alternative energy, other than fossil fuels and the exponential growth in the energy demand has sprouted interest in the development of wind turbines in the past years. Today, wind energy is one of the major sources of renewable energy with the total installed capacity of $600 \mathrm{GW}$ [3] as of 2018. The IEA roadmap anticipated that $18 \%$ of the global energy demand will be met by wind energy by the end of 2050 [4]. The early VAWTs are in construction based on the aerodynamic drag simply, whereas the reverse drag is eliminated by covering the advancing blade to generate net torque. Later, it was realized that the lift force is more efficient than drag and in order to achieve sufficient lift, the blade shape has to be different on the top and bottom side. Lift based Darrieus turbine was invented by G.J.M. Darrieus, a French aeronautical engineer in 1925 [5] and subsequently obtained a U.S. patent in 1931. Though Darrieus built smaller models to establish his invention, a $7-\mathrm{kW}$ power generation model was built in 1950 by Morel [6]. As the research on VAWT gained momentum during early 1980s numerous configurations have been conceived and put to test. Due to early failures and limited funding compared to HAWT, various innovative concepts have not been fully explored or not commercialized.

The evaluation of wind turbines is categorized into three, based on their power capacities. Turbines of power capacities less than $50 \mathrm{~kW}$ are small scale wind turbines, whereas medium scale wind turbines have their power capacities in the range of $50 \mathrm{~kW}$ to $500 \mathrm{~kW}$. Power capacity above $500 \mathrm{~kW}$ is termed as large or utility-scale wind turbines. The current study explores each configuration in detail with an emphasis on their structural arrangements shedding light on the aerodynamic behaviours in low wind speed. The collective findings will add profound knowledge to the VAWT community and will aid in the development of efficient VAWTs in the future.

\section{Small Scale Wind Turbines ( $<50 \mathrm{~kW}$ )}

The small-scale wind turbines play a key role in decentralized power generation. The renewed interest on these turbines is attributed to nano and micro grid development together with the rapid advancements in the energy storage technologies. Flow in built areas is highly turbulent and complex [7]. The horizontal wind speed is determined by the surface roughness as given in the Equation (1), where $Z$ is the vertical coordinate, $U_{\infty}$ the friction velocity, $\mathrm{k}$ the von Kármán constant (0.41), $\Delta Z$ the zero-plane displacement and $Z_{0}$ the roughness height. The zero-plane displacement is the height at which the wind speed is approximately zero due to tall objects such as buildings. The roughness height is a measure to account for the degree of roughness of the terrain.

$$
U_{\infty}(z)=\frac{u f}{k} \ln \left(\frac{Z-\Delta Z}{Z_{0}}\right)
$$

Hence the chosen wind turbine should be able to start and generate substantial power even in low turbulent winds prevalent in the urban environment. 
Other factors that determine the suitability of a turbine on buildings are aesthetics, noise, shadow flicker, cost, bird-friendly and ease of maintenance. Tower for small wind turbines has to be designed to facilitate easier maintenance. Though guy wire towers are popular for its low cost, tubular towers are preferred for aesthetics.

\subsection{Conventional Savonius Turbine}

In typical VAWT, the blades are arranged vertically and rotate around the vertical axis. Some of the niche advantages of Savonius turbines are insensitive to the wind direction, ease of maintenance by placing the drive train components on the ground [8], lo manufacturing cost of blades and reduced tower height. For urban applications, Savonius turbines are preferred than the Darrieus turbines despite its lower efficiency ( 15\%) [9]. Savonius turbines are drag based and can generate power in turbulent and low wind speed prevalent in the built-up area. Myriad studies are carried out in the past unfolding the flow pattern around the Savonius buckets and its blade wake interactions. Numerous experimental studies [10] established the critical parameters of the turbine such as effect of end plates, optimum end plate diameters, effect of aspect ratio, influence of bucket spacing, bucket overlap, number of buckets, number of stages, interference of shat, effect of deflecting plate, helical and straight blades as shown in Figure 1. The aspect ratio can be defined as the ratio between the height to the diameter of the rotor. It was concluded through experimental results that the efficiency increases with the aspect ratio [11]. The past research shows that the end plate significantly improves the power performance by preventing the fluid flowing over the blades and thus maintaining the pressure difference between the concave and the convex side over the height of the rotor [12]. Sivasegaram [13] conducted an experimental investigation on the effect of the end plate and found that optimum end plate diameters are 1.1 times the rotor diameter. According to Kamoji [14], the maximum power coefficient decreases with increase in overlap ratio, whereas the experimental study by Alexander [15] reveals that, the efficiency increases with the overlap ratio for the tested values of -0.07 to 0.22 [16]. Helical Savonius rotor reduces the peak torque [17] by spreading over wide azimuthal angle substantially reducing the peak alternating stress on buckets. Despite these efforts, the maximum efficiency of the Savonius turbines hovers around $18 \%$. The maximum commercially available Savonius turbine has the power capacity of $10 \mathrm{~kW}$ manufactured by Wind Side [18]. Compared to HAWT, Savonius turbines have much better prospects in terms of return on investment in low wind.

\subsection{High Wind Resilience Savonius Turbine}

Savonius turbines operate by drag force, through diminutive lift force also contributes to the torque. Increase in wind speed invariably increases the drag force. The drag force, if not converted to torque will result in higher wind load. The obstacle plate used to reduce the negative moment on the convex side [21] of the 


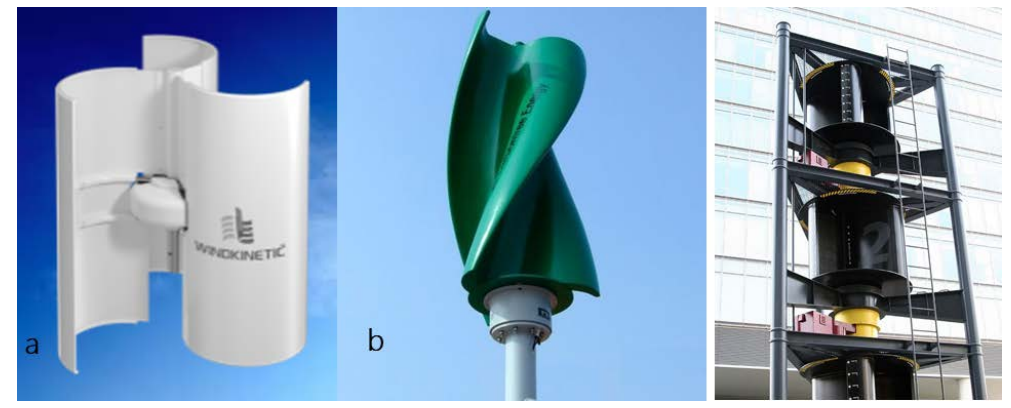

Figure 1. (a) Savonius turbines with Straight bucket [19]; (b) Helical bucket; (c) Multi-stage Savonius turbine [20].

blade by directing the wind towards the concave side tends to increase the wind load, though the deflecting plate increases the efficiency to $27 \%$ [22]. As per IEC61400-2, for small wind turbines, the wind load is calculated based on the frontal area [23]. The frontal area of the Savonius rotor does not change in the event of high winds. This is not the case with HAWT as they are equipped with furling mechanism, in which the rotor plane orients to the wind direction exposing the minimal frontal area to the wind. The aligning force is generated through the difference in the aerodynamic thrust between the tail and the rotor. Researchers have attempted to introduce such a mechanism to Savonius turbine to reduce the wind load and have achieved notable success. As the concave shape of the Savonius buckets has the drag coefficient of $\sim 2.2$, whereas the cylinder has the drag coefficient of $\sim 0.47$, converting the semicircular buckets to cylindrical shape was proposed as a solution by Patrick-Leroy [24]. The linkages attached to the centershaft rotate the semicircular buckets to one cylinder. Though the experimental studies reveal that the wind loads are reduced by $20 \%-30 \%$, the cylinder at high winds will induce von Karman vortices [25] which will compound the wind loading with alternating moment and vibrations. Telescopic Savonius Turbine (TST) was proposed as a potential solution to curtail the wind load as shown in Figure 2. The telescopic turbine is able to expand and retract based on wind conditions. The ability of the turbine to modify its frontal area in accordance with the wind speed helps the wind turbine to maintain its power and wind loads within the acceptable limits. Numerical simulation shows that the wind load of TST can be reduced by $~ 60 \%$ [26] compared to conventional Savonius turbine. Savonius turbines are not preferred for the power capacity more than $10 \mathrm{~kW}$ due to the higher wind loads which demand heavier support structures.

\subsection{Straight Bladed Darrieus Turbine}

The straight bladed Darrieus turbine is the simplest of the type as they are easier to manufacture, transport and assemble on the turbine. Numbers of blades for a given power capacity are based on the average wind speed on the installation site, rpm of the machine and starting characteristics. A two-straight bladed Darrieus rotor is commonly referred as H-Rotor [27] and more than two-bladed 
turbines are referred as Giromill [28] as shown in Figure 3. Though in most cases the blades are parallel to the axis of rotation, delta rotor, diamond rotor, $\mathrm{V}$ or $\mathrm{Y}$ rotor was reported to have their blades inclined to the axis of rotation. The maximum coefficient of performance $(\mathrm{Cp})$ of a straight bladed turbine is in the range of $0.25-0.35$. The $\mathrm{Cp}$ of the turbine is highly influenced by the solidity of the turbine defined by the ratio between the blade area to the swept area. Solidity can be increased by increasing the number of blades or increasing the chord length of the blades. The solidity of a straight bladed Darrieus rotor has a major impact on the starting characteristics of the turbine. The experimental study by Baker [29] shows that the static torque coefficient is higher for three bladed turbines compared to a two-bladed turbine. The blade mounting struts can be steel tubes which reduces the manufacturing cost and available in a wide range of diameters with various wall thicknesses. Straight bladed Darrieus turbines are not preferred for urban applications due to its lower performance in low and turbulent winds. Unable to self-start at wind speeds below $4 \mathrm{~m} / \mathrm{s}$ [30] is a major drawback hindering these turbine installations on rooftop. The past studies on self-starting reveal that the flow detachment from the blades at low Reynolds number (Re) and high Angle of Attack (AoA) results in the generation of low lift significantly reducing the net torque [31]. Another shortcoming of smaller Darrieus turbines is the rotational speed. Darrieus turbines are comparatively slow rpm machines than HAWT. The increased generator size for the same power capacity leads to an increase in cogging torque [32], offering higher resistive
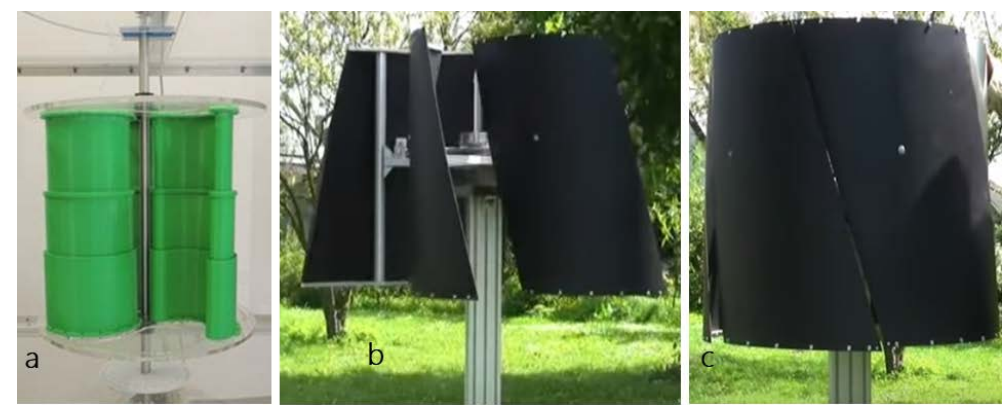

Figure 2. (a) Savonius telescopic turbine [26]; (b) Patrick Savonius turbine in operating configuration; (c) In closed configuration at high winds [24].
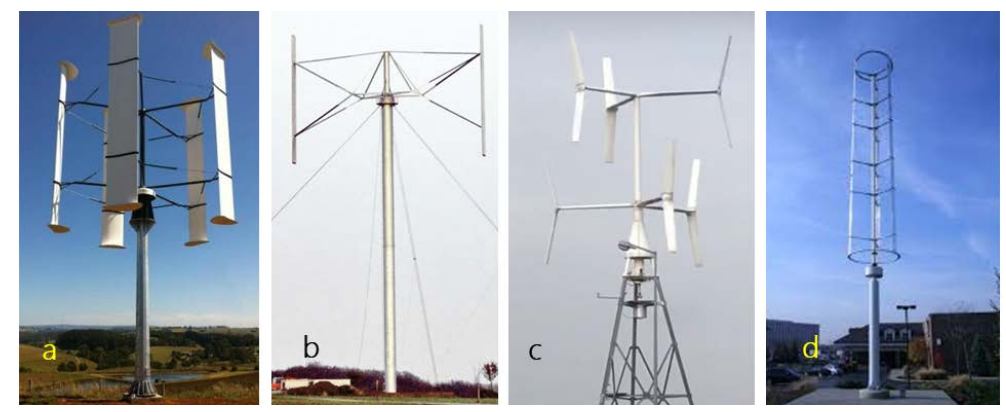

Figure 3. (a) High solidity Giromill [33]; (b) H-rotor [34]; (c) Two-stage Giromill [35]; (d) High aspect ratio Darrieus turbine [36]. 
torque against rotation. In spite of these drawbacks, aesthetically pleasing and simple construction led to the development of innovative small-scale Darrieus wind turbines. The straight bladed Darrieus turbines are commercially available in power capacities from $500 \mathrm{~W}$ to $1.5 \mathrm{MW}$.

\subsection{Helical Darrieus Turbine}

The helical turbine was proposed by Gorlov in 1995 [37]. Compared to the straight bladed turbine, helical bladed turbine offers noteworthy advantages such as enhanced self-starting capability, low noise, increased blade life, low vibrations and reduced peak stress in the blades [38]. The self-starting capability is improved by the reduction of AoA and the ability of the blades to accelerate beyond the dead band [39]. It is also evident from the past studies that the stall angle is increased due to the boundary layer attachment by the introduction of spanwise flow by the helical blades. Tailored airfoils are proposed to delay stall [40]. The helical angle of the blades also has a significant impact on the stall angle. The experimental comparison between straight bladed Darrieus turbine and the helical turbine reveals that the peak $\mathrm{Cp}$ of the helical turbine is, in fact, lower than the straight bladed turbine. The vibrations are reduced due to continuous wake rather than vortices in the case of straight bladed Darrieus turbine [41]. On the negative note, the helical blade manufacturing cost is higher compared to straight blades. The only choice of manufacturing the helical blade is through the mould, whereas the straight blades can be manufactured by aluminium extrusion. Though most of the helical turbines are three-bladed, turbines with two bladed and five-bladed are reported. Increase in the number of blades tends to reduce the operating Tip Speed Ratio (TSR). Blade tip loss and blade wake interactions are highly pronounced for turbines of three-bladed or more. Commercial helical turbines are prevalent in the power capacity of $2-10 \mathrm{~kW} \cdot 7.5 \mathrm{~kW}$ model was manufactured by VWT power as qr6 [42], the current generation turbines. The three-bladed turbines have the swept area of $16 \mathrm{~m}^{2}$ and survival wind speed of $52.5 \mathrm{~m} / \mathrm{s}$ with maximum rpm of 260 . The blade fixing arms are made of carbon fibre, which reduces the weight of the rotor and thereby aids in self-starting by reducing the inertia [43]. Another similar manufacturer of the helical turbine is Turby, which is a research outcome from the Delft University of Technology. The $2.5 \mathrm{~kW}$ turbine reaches its output at $14 \mathrm{~m} / \mathrm{s}$. The turbine is optimized for rooftop installation reaching an efficiency of $40 \%$ even at skewed flow. The qr6 turbine and the Turby are shown in Figure 4.

\subsection{J-Bladed Turbine}

As self-starting and the low-speed behaviour are crucial for a small wind turbine, Darrieus community is in constant search for a solution that can address the above said challenges. J-profile was conceived by researchers and later adopted by manufacturers around the world. The J-Profile on the blade is formed by removing a portion on the pressure side of the airfoil [45]. The choice of the airfoil 
is mostly symmetric NACA series though the use of cambered airfoil is reported. The opening length and position along the chord is a parameter for optimization based on the prevailing wind speed [46]. Different opening ratio (Chord length/Opening length) has been adopted by manufacturers to circumvent the patents on J-Blade. The opening on the blades can be continuous or it can be intermittent. For a smaller blade length $(\sim 4 \mathrm{~m})$ the opening can be continuous, for the higher blade length of $\sim 8 \mathrm{~m}$, the blade opening can be intermittent as shown in Figure 5. A continuous opening for a longer blade will result in bending along the length due to centrifugal forces that are not supported by arms. Poring over the numerical simulation reveals that, the J-blade turbine operates both in lift and drag mode dictated by the opening ratio [47]. The cavity in the blade acts as a drag bucket, smaller opening manifests the turbine more like a conventional Darrieus rotor, whereas larger opening results in the turbine operating g more mon drag force similar to a Savonius rotor. Cost of blade manufacturing can be substantially reduced for J-blade, as the blades can be manufactured by extrusion for smaller length and bending the low carbon sheets with sufficient ribs welded. Employing aluminium material for blade manufacturing paves the way for recycling of blades after the lifetime of the turbine. The study performed by Yusaku [48] shows that the turbine has higher $\mathrm{Cp}$ in the low Reynolds number region and as the TSR increases, the conventional Darrieus rotor outperforms. This can be attributed to the loss of lift due to the flow detachment in low Re. The peak torque amplitude is found to be lower and widespread over larger azimuthal angles. The efficiency of the J-bladed turbine lies in between Savonius-Darrieus hybrid rotor and conventional Darrieus rotor.

\subsection{Curved Bladed Turbine}

The curved bladed rotor was derived from the phi rotor [52] developed during the earlier days of VAWT. The primary difference between the curved bladed rotor and the phi rotor is that the ends of blades are attached to the tower in the case of phi rotor, whereas in the curved bladed rotor it is free. The curved blades are attached to the tower through struts [53]. Presence of struts has a greater influence on the torque generation due to the resistive torque by parasitic drag. In large turbines, struts are made of symmetrical airfoils to reduce the parasitic drag. In both cases, the tower can be rotating or non-rotating. Phi rotor design is prevalent for turbines of capacity more than $50 \mathrm{~kW}$, the curved rotor designs are suitable for small turbines of capacity $\sim 10 \mathrm{~kW}$. The struts are directly attached to the top flange of the axial flux generator as shown in Figure 6 . The ring bearing in the generator can sustain greater moment load than deep groove ball bearings of similar size. From the aerodynamics perspective, curved rotor and the H-rotor has notable differentiation. The Re of the H-rotor blades is uniform along the length of the blades, whereas in the curved blades the Re is higher at the center of the blade length [54]. The changes in Re results in an earlier dynamic stall close to the root. This, in turn, induces more blade tip vortices re- 
sulting in lower $\mathrm{Cp}$. Curved bladed rotor is aesthetically pleasing than H-rotor and hence a suitable candidate for rooftop installations. Blade manufacturing is a comparatively complex than straight blades. Smaller curved blades are manufactured by using glass fibre through moulding process [55]. Larger curved blades are manufactured through extrusion process followed by bending by a skilled worker. Since the larger curved blades are manufactured in sections, there is a possibility of using different airfoils for different sections [56]. Small scale curved blades are manufactured by Greef up to $2 \mathrm{~kW}$ as seen in Figure 6. The $2-\mathrm{kW}$ turbine has a maximum rpm of 160 with the blades manufactured by using Fiber Reinforced Plastic (FRP). The rated wind speed and the startup wind speed are $11 \mathrm{~m} / \mathrm{s}$ and $2.8 \mathrm{~m} / \mathrm{s}$ respectively. The startup torque required to accelerate the rotor was claimed to be less than $0.3 \mathrm{Nm}$.
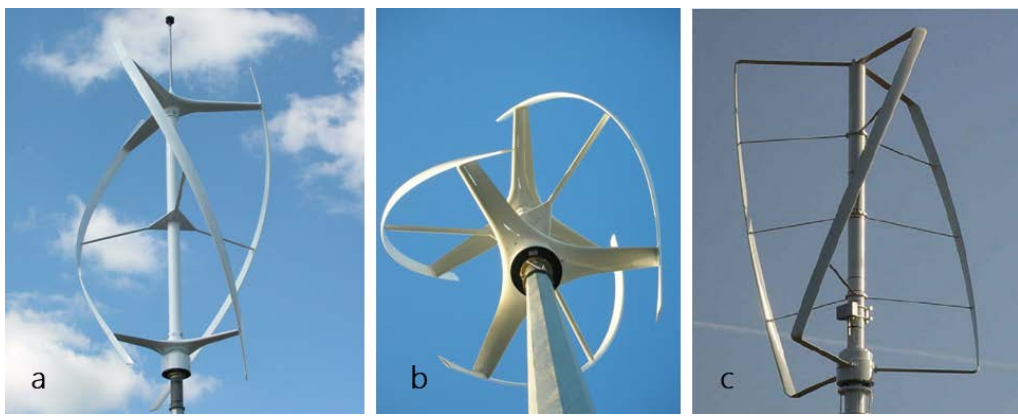

Figure 4. (a) Quietrevoultion qr6 [42]; (b) Bottom view of qr6; (c) Turby [44].
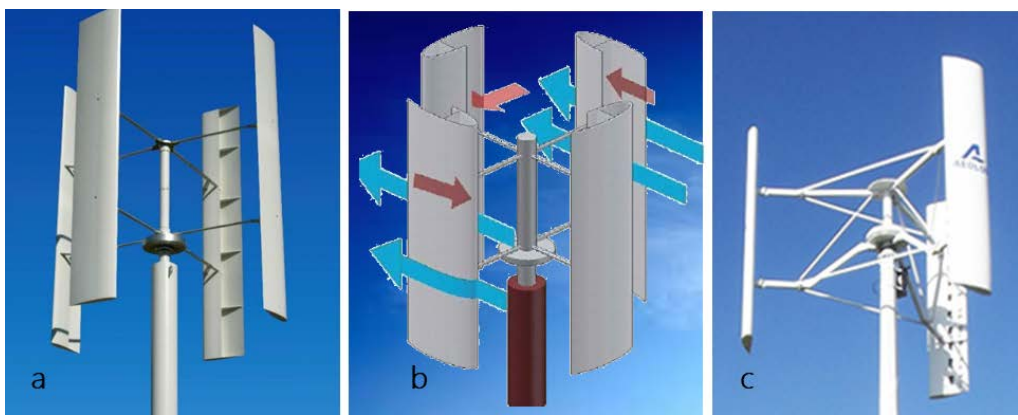

Figure 5. (a) Full length J-profile blade [49]; (b) Operating principle of J-Blade [50]; (c) Intermittent J-profile blade for $10 \mathrm{~kW}$ [51].
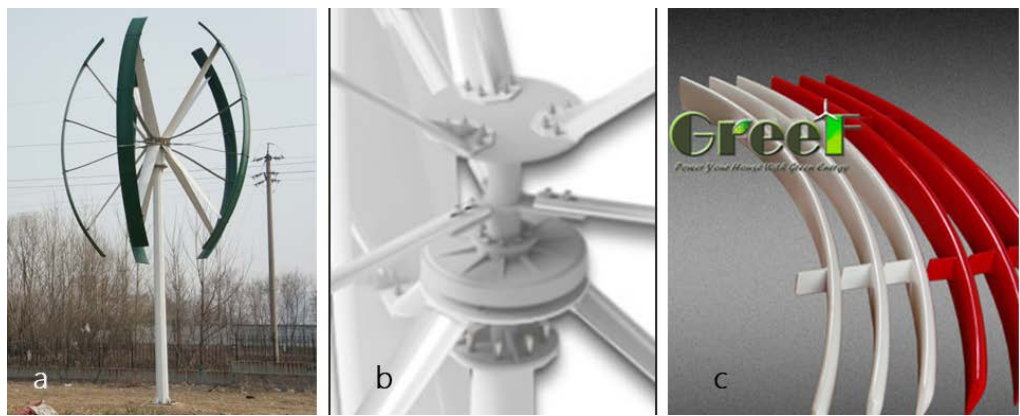

Figure 6. (a) Curved blade assembled on turbine; (b) Struts of curved blade attached to center shaft; (c) Curved blades manufactured by Greef energy [57]. 


\subsection{Electrical Start Darrieus Turbine}

For maximum energy output, it is necessary for the turbine to accelerate to the rated rpm in a shortest possible time. Wind turbines are either connected to the electrical grid or to an energy storage system such as battery and in either case, it is possible to use the energy to accelerate the rotor to the rated rpm. Since most of the turbines use direct drive permanent magnet generator [PMG], Liu [58] proposed a solution in which the generator can operate as a motor during starting and low wind. As the rotor accelerates beyond the dead band and gains sufficient rpm, it can operate as a generator producing power [59]. The proposed solution can reduce the cost involved in high voltage components as the windings demand only low voltage components. The concept of active motoring was simulated on a $5 \mathrm{~kW}$ HAWT by Aner [60] with two blades accelerated typically in $12 \mathrm{~s}$ to the rated $\mathrm{rpm}$ at $10 \mathrm{~m} / \mathrm{s}$ wind speed. Though the motoring start has negligible impact on the peak power coefficient of a turbine, the significant startup time reduction aids in maximizing the energy extraction. Cogging torque [32] is an inherent characteristic of any PMGs arises from cogging between magnets and the armature windings and can be measured by the torque required to rotate the shaft under no load. The electric start can provide an initial acceleration, but may not able to sustain the low wind speed rotation and hence will not be suitable for Darrieus turbines operating at low wind speed sites. A frequent start and acceleration may consume a considerable amount of power, which will decrease the annual energy production. One such electrical start turbine was commercially manufactured by Cleanfield Energy. V3.5 model offered by the firm is $3.5 \mathrm{~kW}$ three-bladed turbine, reaching its rated power at $12.5 \mathrm{~m} / \mathrm{s}$. The turbine has a maximum rpm of 190 with a blade length of $3 \mathrm{~m}$. The turbine was developed and tested extensively by National Research Council (NRC) of Canada. Another innovative turbine was developed by Apple Wind. The turbine has lower strut of airfoil shape, while the upper strut has been replaced by the bar. The bar will be subjected to tensile force due to centrifugal force of the blades. The current arrangement will reduce the parasitic drag due to struts as seen in Figure 7. The lack of endplates on the top end of blades will generate blade vortices decreasing the net torque.

\subsection{Innovative Darrieus Turbines}

The continuous research on the Darrieus turbine has yielded many innovative designs, yet a very few concepts have the potential to be scaled up for commercial purpose. These turbines are optimized for low wind speed and are economical. An airfoil that is capable of maintaining the lift over high AoA without significant increase in drag will be an apt choice for Darrieus turbines [63]. Airfoils are modified such as trailing edge cavity modification [64] was found to enhance energy yield. Kline [65] (KF) conceived airfoils with abrupt discontinuity claiming to have enhanced lift. Though the airfoil doesn't outperform in the pre-stall region, it demands attention for its aerodynamic behaviours in the post-stall re- 
gion when the step is located on the suction side of the airfoil as reported by Mishriky [66]. The new airfoil KF-N-21 was created by introducing the step discontinuity borrowed from the KF airfoil on the suction side of the NACA 0021 airfoil. In order to create maximum drag during the reverse flow to aid in the startup, the depth of step is located at $18 \%$ c, while the maximum thickness of airfoil is $21 \%$ c [67]. The step length is $50 \%$ c and originates at $30 \%$ c from the leading edge, though location near to the trailing edge is favourable for high lift coefficient. The experimental comparison with conventional turbines reveals that the turbine $\mathrm{Cp}$ has been increased by $13 \%$ at low Re. Another innovative turbine is Double Darrieus (DD) rotor. The proposed DD rotor comprises two sets of blades sharing a common shaft [68]. The outer rotor hereafter referred as the primary rotor (PR) has three straight blades of NACA 0018 and inner rotor hereafter referred as the secondary rotor (SR) has three blades of NACA0018. Experimental comparison with conventional Darrieus shows that starting torque is significantly higher and the turbine is able to generate substantial power even at low wind speed. Characteristics of this turbine at high wind speed are not assessed yet. The third innovative design is the Adaptive Hybrid Darrieus Turbine (AHDT), which combines both the advantages of Darrieus and Savonius, yet overcoming the issues of Hybrid Savonius Darrieus design. The Savonius buckets can slide on the Darrieus rotor strut to form a cylinder thereby eliminating the turbulent wake flow affecting the Darrieus rotor performance. The three primary types of Darrieus rotors discussed above are shown in Figure 8.

\subsection{Hybrid Savonius-Darrieus Turbine}

The Savonius turbines are known for its higher starting torque, while the Darrieus turbines are notorious for poor starting torque. Obviously, the curious idea is to combine both the rotor to supplement each other [72]. At low wind speeds $(<3 \mathrm{~m} / \mathrm{s})$ combined machine demonstrates the characteristics of Savonius rotor, while on high winds $(>4 \mathrm{~m} / \mathrm{s}$ ) the combined machine will behave as conventional Darrieus rotor. Two configurations are practically feasible to combine a Savonius and Darrieus rotor. The Savonius rotor can be placed either above or below the Darrieus rotor or the Savonius rotor can be nested inside the Darrieus rotor. The placement of the Savonius rotor outside the Darrieus rotor tends to increase the length of the rotating shaft, which in turn will lead to vibrations. Hence pragmatic way is to place the Savonius rotor nested with Darrieus rotor. Based on the above idea, a number of past studies are conducted both experimentally and computationally. The objective of all these studies is to optimize the Savonius rotor diameter for maximum low wind performance and to maintain the $\mathrm{Cp}$ of the Darrieus rotor at high winds by minimizing the effect of Savonius rotor. The results show that the starting torque of the combined machine is much higher than the Darrieus rotor, while the peak Cp is attained at lower TSR [48]. The maximum operating TSR for the combined machine is $1-1.2$. It has to be noted that the maximum TSR for a Savonius rotor is 1 , and any attempt to oper- 
ate beyond TSR 1 will generate negative torque. While the Darrieus rotor operates at TSR 3 - 6 [73]. This mismatch between the peak performance of two rotors is a crucial problem limiting the further development of these hybrid turbines. Potential solutions have been proposed to address the above problems associated with Darrieus Savonius rotor integration as shown in Figure 9. Mousavi [74] proposed to disengage the rotors when the Darrieus rotor, accelerates beyond the TSR 1 . Though the solution is technically feasible, the energy captured by Savonius rotor after disengagement will not contribute to the total energy output and the wake generated by Savonius rotor still exist [75]. A promising strategy to eliminate the wake of Savonius rotor will brand this hybrid rotor as a potential solution for low wind speed operation.
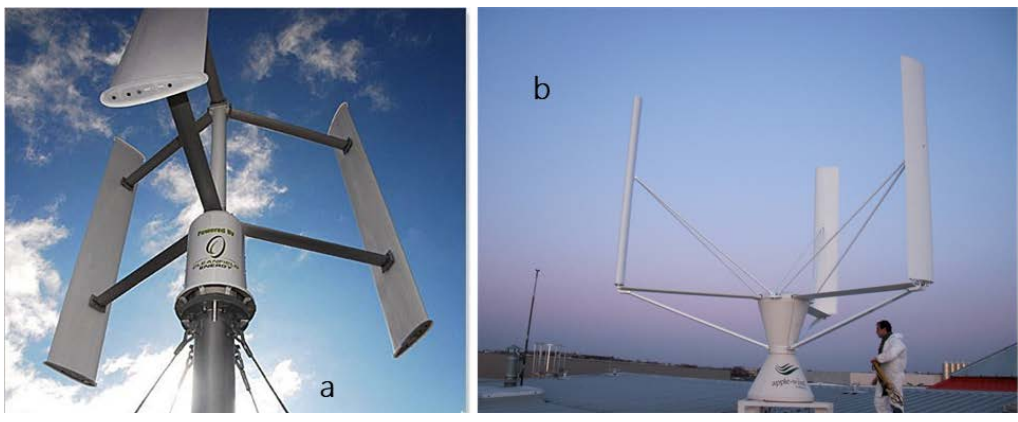

Figure 7. (a) Darrieus turbine with electrical start [61]; (b) Darrieus turbine with variable geometry blades [62].
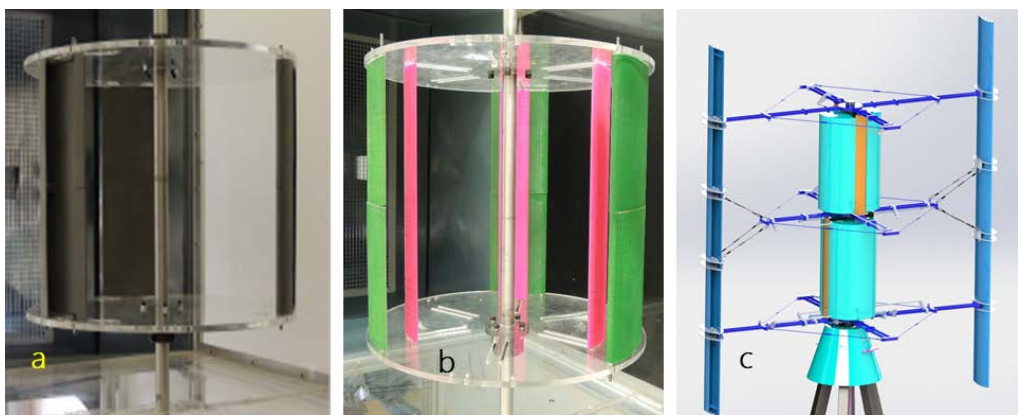

Figure 8. (a) Darrieus rotor with KF-N-21 airfoil [69]; (b) Nested Darrieus rotor [68]; (c) Adaptive Darrieus hybrid turbine [70] [71].
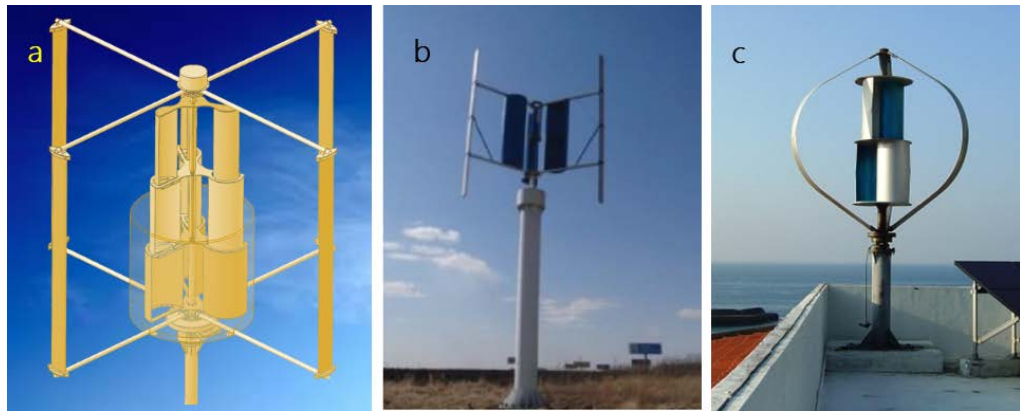

Figure 9. (a) Darrieus Telescopic Savonius turbine [71]; (b) Giromill turbine with Savonius rotor [76]; (c) Curved bladed Darrieus with two-stage Savonius rotor [77]. 


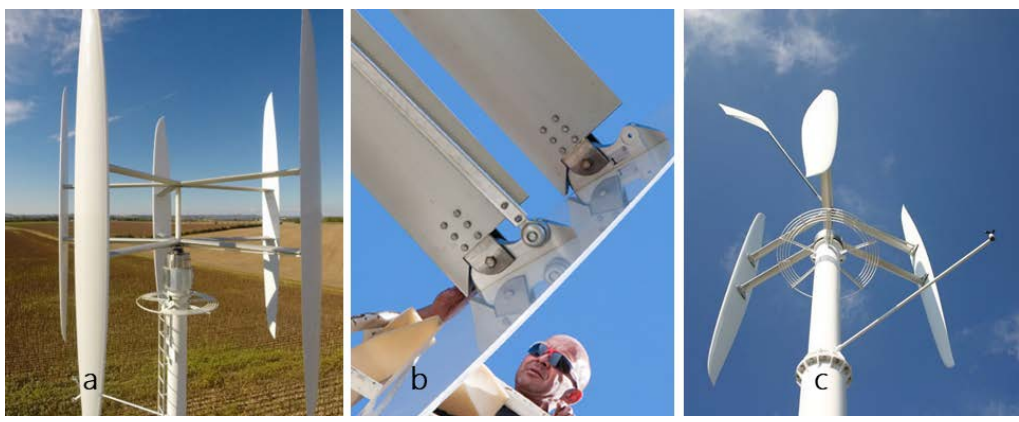

Figure 10. (a) Active pitching [85]; (b) Blade linkages for pitching; (c) Passive pitching by sensing wind direction [86].

\subsection{Blade Pitching Darrieus Turbine}

Blade pitching was once proposed for large wind turbines, as integrating the system in small wind turbine is costly and complex. Due to the advent of actuation systems [78] and reduced cost of the associated electronics, pitching system can be implemented in small Darrieus turbines of capacity as low as $10 \mathrm{~kW}$. Though the Darrieus rotor may look simple, the aerodynamics associated with it is much more complex than HAWT. The fixed blades encounter a wide range of AoA from $0^{\circ}-360^{\circ}$ due to change in the relative velocity. Such a wide AoA constantly push the blades to stall. Due to hysteresis inflow, the flow may be detached even the AoA reduces. To keep the blades at optimum AoA, the blade pitching is a viable solution. Effect of blade pitching is well studied through Double Multiple StreamTube (DMST) [79]. The blades can be pitched either actively or passively. The active pitching is achieved by using closed-loop system actuated by motor for small wind turbines. Considerable amount of power is needed to actuate the motor. The advantage of active pitching compared to passive pitching is that the blades can be pitched individually [80]. The closed-loop system monitors the wind speed and wind direction and pitches the blade accordingly. This generates higher starting torque as all the blades take part in torque generation [81]. A closer investigation of the torque generated by the single blade for one complete revolution reveals that the peak positive torque is generated at upwind half, and smaller negative torque is generated in downwind half. Active individual blade pitching helps to reduce the negative torque which is not possible with passive pitching [82]. The passive pitching relies on the centrifugal force of the blades, in which the hinged blade is allowed to offset at a controlled manner. The passive pitching will increase the negative torque but the positive torque will increase comparatively more [83]. Hence active pitching is effective in increasing the overall performance of the turbine as shown in Figure 10. The past study by Paraschivoiu [84] shows that effective pitching can increase the annual energy yield by $30 \%$. The future large Darrieus turbines will be equipped with blade pitching system for its advantages.

\section{Conclusions}

The current review provides an overview of the extensive development of 
VAWT in the 21st century. Both the Savonius and Darrieus have seen tremendous technological advancements. Myriad studies on these rotors impart profound knowledge on flow physics around these rotors, structural behaviours, different configurations specific to the applications and unsolved challenges. Though Savonius turbines have not been scaled to medium or large-scale power generation till now due to the high wind load demanding large support structures, it has niche applications such as powering up sensors, security devices in a rugged environment. The low cost and simple construction enable these turbines to be deployed in large numbers. Hence Savonius turbines have much better prospects in terms of micro power generation. Interesting findings of Savonius rotors has resulted in the development of aesthetic shapes for urban applications.

The intense research on Darrieus rotor over the past 30 years let to the development of megawatt-scale turbines which will be detailed in the next part of this review. Innumerable challenges have been addressed all the way that was once limiting these turbines during the initial days of development. Multiple innovative concepts on Darrieus rotor, bolster the possibility for efficient VAWT than HAWT. Continuing research on Darrieus rotor such as AHDT is promising, imperative to transform as a low wind speed device. New limitations in HAWT unfolds as the size increases shifting the focus on Darrieus rotor as an alternative.

\section{Conflicts of Interest}

The authors declare no conflicts of interest regarding the publication of this paper.

\section{References}

[1] Sutherland, H.J., Berg, D.E. and Ashwill, T.D. (2012) A Retrospective of VAWT Technology. Sandia Report, SAND2012-0304.

[2] Amano, R.S. (2017) Review of Wind Turbine Research in 21st Century. Journal of Energy Resources Technology, 139, Article ID: 050801. https://doi.org/10.1115/1.4037757

[3] World Wind Energy Association (2019). https://wwindea.org/information-2/information/

[4] International Energy Agency (2019) https://www.iea.org/renewables2018/

[5] Timmer, W. and Van Rooij, R. (2003) Summary of the Delft University Wind Turbine Dedicated Airfoils. ASME_Journal of Solar Energy Engineering, 125, 488-496. https://doi.org/10.1115/1.1626129

[6] Liserre, M., Cardenas, R., Molinas, M. and Rodriguez, J. (2011) Overview of Multi-MW Wind Turbines and Wind Parks. IEEE Transactions on Industrial Electronics, 58, 1081-1095. https://doi.org/10.1109/TIE.2010.2103910

[7] Karthikeyan, B., Negi, P.S. and Srikanth, N. (2016) Wind Resource Assessment for Urban Renewable Energy Application in Singapore. Renewable Energy, 87, 403-414. https://doi.org/10.1016/j.renene.2015.10.010

[8] Kato, Y. and Seki, K. (1981) Vertical Axis Wind Turbine Designed Aerodynamically at Tokai University. Presented at Joint Symposium-Tokai University and Technical 
University of Budapest, October 1981, 31.

[9] Akwa, J.V., Vielmo, H.A. and Petry, A.P. (2012) A Review on the Performance of Savonius Wind Turbines. Renewable and Sustainable Energy Reviews, 16, 3054-3064. https://doi.org/10.1016/j.rser.2012.02.056

[10] Altan, B.D. and At1lgan, M. (2008) An Experimental and Numerical Study on the Improvement of the Performance of Savonius Wind Rotor. Energy Conversion and Management, 49, 3425-3432. https://doi.org/10.1016/j.enconman.2008.08.021

[11] Sheldahl, R.E., Feltz, L.V. and Blackwell, B.F. (1978) Wind Tunnel Performance Data for Two- and Three-Bucket Savonius Rotors. Journal of Energy, 2, 160-164. https://doi.org/10.2514/3.47966

[12] Fujisawa, N. and Gotoh, F. (1992) Visualization Study of the Flow in and around a Savonius Rotor. Experiments in Fluids, 12, 407-412. https://doi.org/10.1007/BF00193888

[13] Sivasegaram, S. (1978) Secondary Parameters Affecting the Performance of Resistance-Type Vertical-Axis Wind Rotors. Wind Engineering, 2, 49-58.

[14] Kamoji, M.A., Kedare, S.B. and Prabhu, S.V. (2008) Experimental Investigations on the Effect of Overlap Ratio and Blade Edge Conditions on the Performance of Conventional Savonius Rotor. Wind Engineering, 32, 163-178.

https://doi.org/10.1260/030952408784815826

[15] Alexander, A. (1978) Wind Tunnel Tests on a Savonius Rotor. Journal of Wind Engineering and Industrial Aerodynamics, 3, 343-351. https://doi.org/10.1016/0167-6105(78)90037-5

[16] Biswas, A., Gupta, R. and Sharma, K.K. (2007) Experimental Investigation of Overlap and Blockage Effects on Three-Bucket Savonius Rotors. Wind Engineering, 31, 363-368. https://doi.org/10.1260/030952407783418702

[17] Damak, A., Driss, Z. and Abid, M. (2013) Experimental Investigation of Helical Savonius Rotor with a Twist of $180^{\circ}$. Renewable Energy, 52, 136-142. https://doi.org/10.1016/j.renene.2012.10.043

[18] Windside (2019). https://www.windside.com/products

[19] WindKinetic (2019). http://wind-kinetic.com/products/50wwindturbine/

[20] Multi-Stage Savonius Turbine (2019). https://www.flickr.com/photos/72396314@N00/115831831

[21] Ogawa, T. and Yoshida, H. (1986) The Effects of a Deflecting Plate and Rotor End Plates on Performances of Savonius-Type Wind Turbine. Bulletin of JSME, 29, 2115-2121.

[22] Golecha, K., Kamoji, M.A., Kedare, S.B. and Prabhu, S.V. (2012) Review on Savonius Rotor for Harnessing Wind Energy. Wind Engineering, 36, 605-645. https://doi.org/10.1260/0309-524X.36.6.605

[23] IEC 61400-2 (2013) Wind Turbines Part 2: Design Requirements for Small Wind Turbines.

[24] Savonius-Balaton (2008). http://savonius-balaton.hupont.hu/174/patrick-leroy-savonius

[25] Karman, T.V. (1941) Compressibility Effects in Aerodynamics. Journal of the Aeronautical Sciences, 8, 337-356. https://doi.org/10.2514/8.10737

[26] Mohan, K.P., Surya, M.M.R., Narasimalu, S. and Lim, T.-C. (2018) Experimental and Numerical Investigation of Novel Savonius Wind Turbine. Wind Engineering, 43, 247-262. https://doi.org/10.1177/0309524X18780392 
[27] Gupta, R. and Biswas, A. (2010) Performance Measurement of a Twisted Three-Bladed Airfoil-Shaped H-Rotor. International Journal of Renewable Energy Technology, 1, 279-300. https://doi.org/10.1504/IJRET.2010.032185

[28] Moran, W.A. (1977) Giromill Wind Tunnel Test and Analysis: Department of Energy. McDonnell Aircraft Corporation, St. Louis, Missouri.

[29] Baker, J. (1983) Features to Aid or Enable Self Starting of Fixed Pitch Low Solidity Vertical Axis Wind Turbines. Journal of Wind Engineering and Industrial Aerodynamics, 15, 369-380. https://doi.org/10.1016/0167-6105(83)90206-4

[30] Worasinchai, S., Ingram, G.L. and Dominy, R.G. (2014) The Physics of H-Darrieus Turbine Starting Behaviour. Proceedings of the ASME Turbo Expo 2014, Düsseldorf, Germany, 16-20 June 2014, V03BT46A008. https://doi.org/10.1115/GT2014-25461

[31] Bos, R. (2012) Self-Starting of a Small Urban Darrieus Rotor. Delft University of Technology, Delft, Netherlands.

[32] Hwang, S.-M., Eom, J.-B., Jung, Y.-H., Lee, D.-W. and Kang, B.-S. (2001) Various Design Techniques to Reduce Cogging Torque by Controlling Energy Variation in Permanent Magnet Motors. IEEE Transactions on Magnetics, 37, 2806-2809. https://doi.org/10.1109/20.951313

[33] SAWT Energy (2007). https://www.sawtenergy.com/

[34] H-Rotor Darrieus Turbine (2006). http://www.reuk.co.uk/wordpress/wind/giromill-darrieus-wind-turbines/

[35] A New Wind Turbines (2010). http://www.anew-institute.com/vawt-videos.html

[36] WindSpire. (2008) http://www.verticalwindturbineinfo.com/

[37] Gorlov, A. (1998) Development of the Helical Reaction Hydraulic Turbine. Northeastern University, Boston.

[38] Shiono, M., Suzuki, K. and Kiho, S. (2002) Output Characteristics of Darrieus Water Turbine with Helical Blades for Tidal Current Generations. The Twelfth International Offshore and Polar Engineering Conference: International Society of Offshore and Polar Engineers, Kitakyushu, Japan, 26-31 May 2002, 859-864.

[39] Blackwell, B. and Reis, G. (1974) Blade Shape for a Troposkien Type of Vertical-Axis Wind Turbine. Sandia National Laboratories, Albuquerque, New Mexico, Livermore, CA.

[40] Kumar, M., Surya, M.M.R., Sin, N.P. and Srikanth, N. (2017) Design and Experimental Investigation of Airfoil for Extruded Blades. International Journal of Advances in Agricultural and Environmental Engineering (IJAAEE), 3, 2349-1523. https://doi.org/10.15242/IJAAEE.U1216208

[41] Purser, P.E. and Spearman, M.L. (1951) Wind-Tunnel Tests at Low Speed of Swept and Yawed Wings Having Various Plan Forms. The National Aeronautics and Space Administration, Washington DC.

[42] Quiet Revolution (2009). https://www.quietrevolution.com/

[43] Castelli, M.R., Dal Monte, A., Quaresimin, M. and Benini, E. (2013) Numerical Evaluation of Aerodynamic and Inertial Contributions to Darrieus Wind Turbine Blade Deformation. Renewable Energy, 51, 101-112.

https://doi.org/10.1016/j.renene.2012.07.025

[44] Turby (2009). https://www.turby.nl/

[45] Chen, J., Yang, H., Yang, M. and Xu, H. (2015) The Effect of the Opening Ratio and 
Location on the Performance of a Novel Vertical Axis Darrieus Turbine. Energy, 89, 819-834. https://doi.org/10.1016/j.energy.2015.05.136

[46] Zamani, M., Maghrebi, M.J. and Moshizi, S.A. (2016) Numerical Study of Airfoil Thickness Effects on the Performance of J-Shaped Straight Blade Vertical Axis Wind Turbine. Wind and Structures, 22, 595-616. https://doi.org/10.12989/was.2016.22.5.595

[47] Zamani, M., Nazari, S., Moshizi, S.A. and Maghrebi, M.J. (2016) Three Dimensional Simulation of J-Shaped Darrieus Vertical Axis Wind Turbine. Energy, 116, 1243-1255. https://doi.org/10.1016/j.energy.2016.10.031

[48] Kyozuka, Y. (2008) An Experimental Study on the Darrieus-Savonius Turbine for the Tidal Current Power Generation. Journal of Fluid Science and Technology, 3, 439-449.

[49] Aeolos-1 kW VAWT (2006). http://www.windturbinestar.com/vertical-axis-wind-turbines.html

[50] Cygnus Power (2010). http://www.cygnus-power.com/products

[51] Aeolos-10 kW VAWT (2008). http://www.windturbinestar.com/10kwv-v-aeolos-wind-turbine.html

[52] Hansen, A.D., Iov, F., Blaabjerg, F. and Hansen, L.H. (2004) Review of Contemporary Wind Turbine Concepts and Their Market Penetration. Wind Engineering, 28, 247-263. https://doi.org/10.1260/0309524041590099

[53] Li, H. and Chen, Z. (2008) Overview of Different Wind Generator Systems and Their Comparisons. IET Renewable Power Generation, 2, 123-138. https://doi.org/10.1049/iet-rpg:20070044

[54] Blackwell, B.F., Sheldahl, R.E. and Feltz, L.V. (1976) Wind Tunnel Performance Data for the Darrieus Wind Turbine with NACA 0012 Blades. Sandia National Laboratories, Albuquerque, New Mexico, Livermore, CA, Medium: ED, Size: Pages: 61.

[55] Islam, M., Ting, D.S. and Fartaj, A. (2007) Desirable Airfoil Features for Smaller-Capacity Straight-Bladed VAWT. Wind Engineering, 31, 165-196. https://doi.org/10.1260/030952407781998800

[56] Ferreira, C.S. and Geurts, B. (2015) Aerofoil Optimization for Vertical-Axis Wind Turbines. Wind Energy, 18, 1371-1385. https://doi.org/10.1002/we.1762

[57] Greef Energy (2009). http://www.greefenergy.com/category/13

[58] Liu, S., Li, S. and He, L. (2012) Direct-Driven Permanent Magnet Synchronous Wind-Power Generating System with Two Three-Level Converters Based on SVPWM Control. Procedia Engineering, 29, 1191-1195. https://doi.org/10.1016/j.proeng.2012.01.111

[59] Kjellin, J. and Bernhoff, H. (2011) Electrical Starter System for an H-Rotor Type VAWT with PM-Generator and Auxiliary Winding. Wind Engineering, 35, 85-92. https://doi.org/10.1260/0309-524X.35.1.85

[60] Aner, M., Nowicki, E. and Wood, D. (2011) Accelerated Starting by Motoring a Grid-Connected Small Wind Turbine Generator. 2011 International Conference and Energy Systems. Issues and Prospects for Asia (ICUE), Pattaya City, Thailand, 28-30 September 2011, 1-7. https://doi.org/10.1109/ICUEPES.2011.6497765

[61] Cleanfield Energy (2010). http://savonius-balaton.hupont.hu/43/cleanfield-energy-ontariocanada

[62] Apple Wind (2008). http://www.kde-energy.fr/apple-wind.html 
[63] Kumar, P.M., Surya, M.M.R. and Srikanth, N. (2017) Comparative CFD Analysis of Darrieus Wind Turbine with NTU-20-V and NACA0018 Airfoils. 2017 IEEE International Conference on Smart Grid and Smart Cities (ICSGSC), Singapore, 23-26 July 2017, 108-114. https://doi.org/10.1109/ICSGSC.2017.8038559

[64] Kumar, P.M., Kulkarni, R., Srikanth, N. and Lim, T.-C. (2017) Performance Assessment of Darrieus Turbine with Modified Trailing Edge Airfoil for Low Wind Speeds. Smart Grid and Renewable Energy, 8, 425-439. https://doi.org/10.4236/sgre.2017.812028

[65] Kline, R.L. and Fogleman, F.F. (1977) Airfoil for Aircraft Having Improved Lift Generating Device. Google Patents: US3706430A.

[66] Mishriky, F. and Walsh, P. (2016) Effect of Step Depth and Angle in Kline-Fogleman (KFm-2) Airfoil. Global Journal of Research in Engineering, 16, 4.

[67] Kumar, P.M., Surya, M.M.R., Kethala, R. and Srikanth, N. (2017) Experimental Investigation of the Performance of Darrieus Wind Turbine with Trapped Vortex Airfoil. 2017 3rd International Conference on Power Generation Systems and Renewable Energy Technologies (PGSRET), Johor Bahru, Malaysia, 4-6 April 2017, 130-135. https://doi.org/10.1109/PGSRET.2017.8251815

[68] Kumar, P.M., Ajit, K.R., Surya, M.R., Srikanth, N. and Lim, T.-C. (2017) On the Self Starting of Darrieus Turbine: An Experimental Investigation with Secondary Rotor. 2017 Asian Conference on Energy, Power and Transportation Electrification (ACEPT), Singapore, 24-26 October 2017, 1-7. https://doi.org/10.1109/ACEPT.2017.8168545

[69] Kumar, P.M., Surya, M.M.R. and Srikanth, N. (2017) On the Improvement of Starting Torque of Darrieus Wind Turbine with Trapped Vortex Airfoil. 2017 IEEE International Conference on Smart Grid and Smart Cities (ICSGSC), Singapore, 23-26 July 2017, 120-125. https://doi.org/10.1109/ICSGSC.2017.8038561

[70] Kumar P.M., Srikanth, N., Anbazhagan, S. and Lim, T.-C. (2017) Optimization, Design, and Construction of Field Test Prototypes of Adaptive Hybrid Darrieus Turbine. Journal of Fundamentals of Renewable Energy and Applications, 7, 245. https://doi.org/10.4172/2090-4541.1000245

[71] Kumar, P.M., Ajit, K.R., Srikanth, N. and Lim, T.-C. (2017) On the Mathematical Modelling of Adaptive Darrieus Wind Turbine. Journal of Power and Energy Engineering, 5, 133-158. https://doi.org/10.4236/jpee.2017.512015

[72] Gupta, R. and Sharma, K. (2012) Flow Physics of a Combined Darrieus-Savonius Rotor Using Computational Fluid Dynamics (CFD). International Research Journal of Engineering Science, Technology and Innovation, 1, 1-13.

[73] Wakui, T., Tanzawa, Y., Hashizume, T. and Nagao, T. (2005) Hybrid Configuration of Darrieus and Savonius Rotors for Stand-Alone Wind Turbine-Generator Systems. Electrical Engineering in Japan, 150, 13-22. https://doi.org/10.1002/eej.20071

[74] Rassoulinejad-Mousavi, S., Jamil, M. and Layeghi, M. (2013) Experimental Study of a Combined Three Bucket H-Rotor with Savonius Wind Turbine. World Applied Sciences Journal, 28, 205-211.

[75] Gupta, R., Das, R. and Sharma, K. (2006) Experimental Study of a Savonius-Darrieus Wind Machine. Proceedings of the International Conference on Renewable Energy for Developing Countries, University of Columbia, Washington DC.

[76] Li, Y. (2019) Straight-Bladed Vertical Axis Wind Turbines: History, Performance, and Applications. IntechOpen, London. https://doi.org/10.5772/intechopen.84761

[77] Hi-VAWT (2010). http://www.hi-vawt.com.tw/en/ds1500w_photogallery.html 
[78] Chopra, I. (2002) Review of State of Art of Smart Structures and Integrated Systems. AIA A Journal, 40, 2145-2187. https://doi.org/10.2514/2.1561

[79] Kumar, P.M., Rashmitha, S.R., Srikanth, N. and Lim, T.-C. (2017) Wind Tunnel Validation of Double Multiple Streamtube Model for Vertical Axis Wind Turbine. Smart Grid and Renewable Energy, 8, 412-424. https://doi.org/10.4236/sgre.2017.812027

[80] Kirke, B. and Lazauskas, L. (1991) Enhancing the Performance of Vertical Axis Wind Turbine Using a Simple Variable Pitch System. Wind Engineering, 15, 187-195.

[81] Chougule, P., Nielsen, S.R. and Basu, B. (2013) Active Blade Pitch Control for Straight Bladed Darrieus Vertical Axis Wind Turbine of New Design. Key Engineering Materials, 569-570, 668-675.

https://doi.org/10.4028/www.scientific.net/KEM.569-570.668

[82] Hwang, I.S., Min, S.Y., Jeong, I.O., Lee, Y.H. and Kim, S.J. (2006) Efficiency Improvement of a New Vertical Axis Wind Turbine by Individual Active Control of Blade Motion. Proceedings of SPIE-The International Society for Optical Engineering, San Diego, California, United States, 5 April 2006, p. 617311. https://doi.org/10.1117/12.658935

[83] Elkhoury, M., Kiwata, T. and Aoun, E. (2015) Experimental and Numerical Investigation of a Three-Dimensional Vertical-Axis Wind Turbine with Variable-Pitch. Journal of Wind Engineering and Industrial Aerodynamics, 139, 111-123. https://doi.org/10.1016/j.jweia.2015.01.004

[84] Paraschivoiu, I., Trifu, O. and Saeed, F. (2009) H-Darrieus Wind Turbine with Blade Pitch Control. International Journal of Rotating Machinery, 2009, Article ID: 505343. https://doi.org/10.1155/2009/505343

[85] Envergate (2012). http://www.envergate.com/en/products/quinta99.html

[86] Envergate (2010). http://www.envergate.com/en/products/quinta20.html 